\title{
On the Content of the Young Child's Right to Health
}

\author{
Zhang Lihong ${ }^{1}$ \\ ${ }^{1}$ China West Normal University, China \\ Correspondence: Zhang Lihong, China West Normal University, China. E-mail: 283702403@qq.com
}

\author{
Received: January 5, 2015 Accepted: March 3, 2015 Online Published: March 27, 2015 \\ doi:10.5539/ass.v11n7p326 URL: http://dx.doi.org/10.5539/ass.v11n7p326
}

\begin{abstract}
The early childhood period, as an independent and special part, determines the characteristics of the content of the young child's right to health. Combined with the rights theory and the living conditions and development questions about the young children, the content of the young child's right to health can be divided into the right to eutocia, the right to food, the right to space and the right to sports etc. Focused on the content of the young child's right to health is not only to widen the field of the research of the right to health, but also to provide a theoretical basis to legislation for safeguarding the young child's health. Though the object and scope of this research focus on the context of Mainland China, its conclusion and analytical framework which is also fitting for other country's children, especially for the children of the other developing country has a universal use for reference and direction.
\end{abstract}

Keywords: the young child's right to health, the right to eutocia, the right to food, the right to space, the right to sports

\section{Introduction}

Based on previous viewpoints, the rights to health include the right to claim concerning eliminating healthy danger, the right to justifiable defense, the right to medical treatment, the right to fundamental medicine acquisition, the right to environmental health, the right to vocational health, the right to reproductive health, the right to sexual health, the right to public health, the right to medical assistance acquisition and the right to product safety relating to health (Lin, 2010). Besides, some scholars also hold the idea that the rights to health include the right to health maintenance, the right to health care, the right to basic medical demand, the right to medical insurance, etc (Littell, Wiggin, \& Dana, 2002). It can be easily noticed that these rights in which the adult-centered value orientation has been reflected are logically belonging to young children. Hence, it is not enough to use sub-rights to analyze and normalize the laws relating to the health of young children. Some people have the viewpoint that the rights of young children to health include (but are not limited to) the following aspects, such as the right to children's health prevention and healthcare, the right to children's health education, the right to children's health environment and the right to children's relief of health infringement (Sun, 2012). This division can initially reflect the particularity and pertinence of the rights of children to health; however, there is certain limitation in terms of using this division to analyze the rights of young children to health. As a relatively independent and special phase, early age determines the particularity of the rights of young children to health. With relevant right theory and the current life status as well as existing problems concerning children's social reality in China, it has been put forward that the rights of young children to health include the right to eutocia, right to food, right to space, and right to sports. Focusing on the rights of young children to health and studying the content construction can not only broaden the research domain of health rights, but also provide theoretical support for legislative guarantee concerning the rights of young children to health.

\section{The Right to Eutocia}

The right to eutocia means the natural delivery of the embryo with the head coming out first from vagina of the mother in accordance with medical standard. Here, the basic conditions for the medical standard of eutocia can be determined by three factors: puerperal force, birth canal and normal position of the embryo which fit with each other. The right has been put forward based on two points. First, eutocia itself can benefit the development and growth of the embryo. In the process of extrusion and pressing, the embryo can exercise his lung ability, which can promote the postnatal development of normal breathing. Immune globulin $\mathrm{G}(\lg G)$ can be passed from maternal body to the embryo in the process of eutocia. Hence, newborns in this way can be endowed with greater 
immunity. Moreover, in the birth canal, the senses of touching, taste and pain, along with sense of embryo's own position can be strengthened, thus promoting the development of the brain and vestibular function, which will also benefit the future movement ability and personality. Second, the right is put forward in response to the high Cesarean section rate in China. According to the report published by WHO on medical authoritative periodical The Lancet, average Cesarean section rate of the three continents (Asia, Latin America and Africa) investigated is $25.7 \%$, while the average rates of Asia and China are $27.3 \%$ and $46.5 \%$ respectively, with China ranking the first among all the 24 countries within the three continents. It can be seen from the investigation results that, not only has China the highest Cesarean section rate, but also non-medical indication is also provided with the highest Cesarean section rate, which is almost 20 50 times of the rate in most countries. It is a special phenomenon in terms of Cesarean section in China." (Pang, 2012) In the 1970s, the Cesarean section rate in China was only around 5\%. Compared with that time, the rate has increased by about 10 times after forty years. Besides, the number has been three times more than the usual Cesarean section rate (15\%) required by WHO.

The causes for the phenomenon can be various. Pregnant woman or other family members may have a misunderstanding for the advantages and disadvantages of Cesarean section; legal institution relating to medical staff protection and medical dispute treatment is unsound; the quantity of midwives is low and the quality of nurses is not high; there is excessively clinical intervention; the utilization and promotion of appropriate delivery aiding technology cannot be implemented; economic orientation, current distribution system and uncoordinated labor value also affect the mother's delivery (Pang, 2012). Changshou No. 3 People's Hospital have an analysis on the reason of Cesarean section among 581 cases in the past four years, which shows that there are 358 cases (61.62\%) with medical indication; there are 223 cases (38.36\%) of Cesarean section resulted from social factors in which there are 107 cases (47.98\%) out of pregnant women's fear of pain, serving as the major social factor; besides, there are 49 cases $(21.97 \%)$ with Cesarean section on a chosen date, ranking the second place; 40 cases (17.94\%) are due to doctors' misguidance, while 27 cases $(12.11 \%)$ are caused by the impelling of registered permanent residence $(\mathrm{Yu}, 2006)$. It can be inferred that the reason of the high Cesarean section rate is completely abnormal, relating to which there are both personal reasons and social causes. If people adhere to the objective of the best interest of the children, we should change the concept and perfect social mechanism timely, and reduce the influence of private interest on eutocia. The practical significance of eutocia right will be thus recognized. In this way, people can straighten out the high Cesarean section rate due to non-medical reasons personally or socially.

\section{The Right to Food}

The right to food is also called the right to foodstuff safety (Xu, 2007). Extension of "food" is richer than that of "foodstuff", with the latter mainly referring to semi-finished products or finished ones. Hence, many agricultural products have been omitted, which is not good for understanding the problems of "in the bite of children". Young children's food should be both safer and more nutritious than adults'. Apparently, these connotations cannot be covered fully by the concept of foodstuff safety right. Therefore, in the research, it is called as the right to food. According to the United Nations Economic and Social Council, the right to food means that consumers have the right to directly acquire or buy enough qualified food through financial means based on their cultural traditions frequently, permanently and without restrictions. The aim is to ensure that people, alone or collectively, can live a dignified life consistent with private need without fear, both physically and spiritually. (UN Commission on Human Rights) "Food is the paramount necessity of the people", which can vividly describe the existence value of the right to food. However, as mentioned by UN report, "It is shocking that there are still millions of vulnerable children dying of hunger in this unparalleled rich world. A civilized world will not allow a child to die of hunger; besides, a child shall not suffer physical or psychological mal-development due to long-term malnutrition. Despite of the fact, there are still such phenomena nowadays, and more than 17,000 children under five die of hunger-related diseases everyday. Till the end of this year, there are over 5 million children dying of hunger-related diseases. Furthermore, tens of millions of children cannot get enough food to maintain a normal life everyday, thus causing physical and intelligential disabilities." (UN Commission on Human Rights)

Based on freedom from want, young children have the entitlement to acquire datum quantity of food to meet the needs of their growth and development both physically and mentally. The right to food is put forward based on two points: first, children are free from want; second, nowadays, there are tens of thousands of children accompanied by shortage of food on a long-term basis in the world. Franklin D. Roosevelt's State of the Union Address, known as Four Freedoms, delivered to the 77th United States Congress on January 6, 1941 is announced four "basic freedoms of human" to the national people, and expressed the determination to realize those freedoms, namely freedom of speech, freedom of worship, freedom from want and freedom from fear. 
Among the four freedoms, freedom from want includes enjoying sufficient medical care, having the right to acquire and maintain health and enjoying sufficient guarantee. Actually, freedom from want will exert great guiding significance on realizing the right to education for young children. Nowadays, the children mentioned above are faced with serious food shortage, which is in accordance with the content in UN report that, "every five seconds, there will be a child under five dying of hunger or hunger-related diseases; every four seconds, there will be one suffering blindness due to lack of vitamin A; in this unparalleled rich world, the number of people suffering from serious malnutrition has increased to 0.842 billion. Once the situation continues, that will be the humiliation for the whole human society. Hence, it is time to enforce the right to food" (UN Commission on Human Rights). On one hand, children in necessity of nutrition supply are faced with hunger; on the other hand, the whole society is faced with unfair food distribution and extremely serious extravagance and waste. Research Group of China Agricultural University has conducted systematic analysis on the protein and fat of leftovers of 2,700 dinners with different scales in large, middle and small cities. Based on conservative predictions, wasted protein from 2007 to 2008 reached 8 million tons, equaling the yearly demand of 0.26 billion people; wasted fat reached 3 million tons, equaling the yearly demand of 0.13 billion people.

For those young children in developing countries, the right to food means acquisition of basic food supply. However, the right can be realized only through sufficient cooperation between international organizations and developed countries in the name of humanitarianism. For young children in China, the emphasis shall be put on two points, namely food must be safe, and nutritious but not excessive. There have been revealed or unfound food safety accidents, such as the accident of melamine milk powder, the first-mouth deprived milk accident for newborns in Tianjin, processing overdue meat by Shanghai Husi Food Co., Ltd. These shocking and heinous food safety accidents have rendered children's food safety to be the priority for the entire society and government. To solve the problems, not only should safe food supply be satisfied, but also proper trophic structure should be guaranteed; that is, young children shall have enough basic nutrition (mainly including protein, fat, carbohydrate, mineral substance, vitamin and water). The two points mentioned can be called the right to food safety and the right to nutrition which are sub-rights of the right to health. In the domain of the right to health, the right to food security is the primary phase of guaranteeing to realize the right to health, while the right to nutrition is the advanced phase of guaranteeing to realize the right to health. Hence, for young children, food security is in the first place while nutrition is in the second place. Ideally speaking, there is no division of primary or advanced phases for children's health. If any, the healthy status would be advanced. Just as Convention on the Rights of the Child says, "States Parties recognize the right of the child to the enjoyment of the highest attainable standard of health". Breast milk for newborns is their best food, but some newborns cannot suck its mother's breast in the first time, they have to be bottle-fed for the misguidance of merchant and the parents' lacking the right knowledge of breast milk. Therefore, it is very necessary that the right to breastfeeding be put forward.

The right to breastfeeding refers to that newborns are entitled to have breast milk after it is delivered from maternal body on time. The right is put forward based on three points, namely superiority of breastfeeding, serious defect with the quality of milk replacer and the fact of decreasing breastfeeding nowadays in China. Relevant researches show that, breastfeeding is beneficial to the healthy growth of infants, because breast milk, especially colostrum, contains rich nutrition required by the infants, which cannot be replaced by any milk product. Besides, it can benefit the recovery of the mother in the puerperium ; breastfeeding can enhance the resistibility and immunity of the infants; it can benefit the digestion of the infants; it can also enhance the emotions between the mother and the child; it is economical, practical, convenient and swift; it is clean and safe; it can reduce infants' allergy while at the same time reduce the rate of ovarian cancer and breast cancer of the mother. Breastfeeding is one of the safest, cheapest, most readily available, universally attainable and feasible ways. Recently, there have been serious food safety problems in terms of milk replacer threatening the health of newborns, such as melamine substandard milk powder accident. According to WHO's standard, there should be at least six month breastfeeding, for which the right to breastfeeding shall last at least half a year.

Researches show that breastfeeding has a decreasing tendency in China in recent years (Yang, 2012; Qian, 2012; Mao, 2012). Like China, in many other parts of the world, breastfeeding is no longer norm (UNICEF, 2006). Factors influencing breastfeeding rate include mother, family and social aspects; pregnancy process, delivery way; the embryo itself, the would-be mother, and the family economy (Hu, 2004; Liu, 2006; Yang, 2012). Among the factors, Cesarean section affects seriously breastfeeding rate. Therefore, guaranteeing the realization to the right to eutocia will benefit the realization of the right to breastfeeding. In order to improve the rate of breastfeeding, favorable household should be created, and social support system for the pregnant women should be provided. Besides, paid vacation system for the parents shall be established, and professional agencies such as 
child care service center shall be founded to provide health education, which will thus promote the realization of the right to breastfeeding.

\section{The Right to Space}

In the contemporary society, the utilization of space has become increasingly important due to lack of land resources, dense urban population, and extremely limited production and living space. With the improvement of the utilization level from 2-dimension use to 3-dimension use, space has acquired unprecedented economic value. Objectively, the right to space shall be legally verified, and the interests of the space shall be legally protected, which promotes effectively the orderly development and usage of the space by right subject and people in need of space resources. In this way, value of space will be made the best use of. Therefore, the earliest research on the right to space in China appears in such fields as economic law and property law. At present, there are three perspectives about whether the right to space can become an independent right, namely the theory about the denial of the right to space, the theory about the independence of the right to space and the theory about comprehensive rights (Wang, 2007). Wang Liming is in favor of the theory about the Independence. Based on his viewpoint, right to space is a new property right, which can be separated from the right to use of construction land, thus becoming an independent real right (Wang, 2007). According to property law, space is connected with land. It is a 3-dimension space within a certain scope over or below the land. As the space of the right to education, it is not only connected with the physical space as infrastructure construction, but also related to the educational environment which affect and promote the growth and development of the children. On the other hand, the emphasis shall put on not only educational physical space, but also the interactive psychological space between children and educators. The right to space relating to the right to education refers to that in order to acquire proper growth and education, certain physical and psychological space are required to meet the qualifications or demands of physiological, psychological and social development. Here physical space mainly includes relatively independent bed, bedroom, activity area, average occupancy volume of interior space as well as exterior play zone of the child in kindergarten, and average occupancy volume of parks or greenbelts in communities or streets. While psychological space mainly includes the educational atmosphere among children and family members, children and teachers, and children and companions. The educational atmosphere can be understood as the sum of emotion, emotional state and favorable or opposed impression about education (Otto Friedrich Bollnow, 1999).

From anthropological perspective, verification for the right to space does not originate from the need of occupation of 3-dimension space centered with land. Instead, it originates from the manor consciousness left during human evolution. As mentioned by commentators, "when you put a name brand on the front door, or put up a drawing on the wall, you are actually behaving in the way of dog or wolf when they are unwarping the hind leg to pee" (Morris, 2010). The manors of the animals are the basis for them to acquire enough food and avoid internecine action of the same kind. After long-term evolution, human is called "the intelligent part of the universe", "in charge of managing fish in the sea, birds in the sky and various living creatures on the ground." (Bible, 1:28) Despite of the fact, people are endowed with animality in many aspects, because "since the ancient primitive life, there are trivial or insignificant changes of naked ape." (Morris, 2010)

For human being, the safest space is "home". "People go out of home and come back home, which is the living place, the place where he is 'at home'. The point is the center to determine other points, and various roads extend from this starting point then turn back here." (Otto Friedrich Bollnow, 1999)The basic form of this kind of safe space is to own a house with protective door, wall and fence. When a man owns such a safe space, he can flinch back to this safe space from the stormy world in case he has been utterly worn out by the external affairs. At home, there will be no disturbance, while he can get more rest and adjustment. In this way, he could once again acquire the extra energies, which will provide him with the maximum health. Hence, home is "a tool fighting against the universe"; it is a space that "the wind may blow through it-the storm may enter-the rain may enter-but the King cannot enter!"

Home, community and kindergarten are the most important physical space for young children. For children in rural areas, they can move in the open air easily, while for children in urban areas, they may face some difficulties in getting enough safe public space due to the increasing commercialization and privatization of urban development. Nowadays, a prominent problem concerning respecting and ensuring the right to space of young children would be the swelling scale of some kindergartens and large class scale. When public resources cannot be fully guaranteed, people would rather let their children study at home than study in kindergarten due to the reason that in such kindergartens, the basic breathing, playing and excreting would be greatly influenced. Admittedly, physical space is important, but children's psychological space is more important. Even if children are living in a mansion with a size of several hundred square meters, they feel stifled psychologically in the case 
that there are no freedom and no choices. Hence, ensuring children's right to space will be beneficial to their healthy growth both physically and mentally. Meanwhile, this act will also lay the solid foundation for the implementation of sports activities and participation rights because the right to space serves as the premise for both the right to sports activities and participation rights.

\section{The Right to Sports Activities}

In the New European Sports Charter (passed in the $7^{\text {th }}$ European Sports Cabinet Summit Meeting in May, 1992), the goal of the Charter is that each government regard sports revitalization as an important factor in human development. According to several principles of Sports Ethics Program, it is important to attach great importance to essential measures applicable to the provisions of this charter.1. All the people have the right to sports activities, especially 1) guarantee young people's right to receive sports guide and learn basic sports skills. 2) guarantee individual's right to take part in sports activities and physical recreation in a safe and healthy environment. 3) make sure that any individual who is interested in sports and has athletic abilities has the right to improve his sports competitiveness and achieve his desire. The right to sports activities refers to children's freedom to take part in various sports activities in order to know the world and develop their own physical ability. Here, the right to sports activities is based on two points: the first one is the requirement of sports in terms of its importance for the physical and mental development of children, and the second one is that in practice, freedom of young child to sports is usually neglected, intentionally or unintentionally.

Life lies in movement. As movement for a new-laid mammal, being able to walk and run quickly soon means living for another day. Living for another day means increasing strength in the process of maturation. For animals, sport means survival, and no sports means death. Even for a majestic-looking and extremely arrogant African male lion, if it is badly injured and cannot move, then it is at the verge of death. Human infants are naturally born "premature infants", and it takes one year for an infant to learn walking since it was born. Compared with animals, human infants need more sports and exercises. However, human beings' self-conceit makes the proverb "Life lies in movement" become a slogan for many adults. Therefore, parents in $21^{\text {st }}$ century should recall the voice of a wise man. When criticizing adults' constraint on infants, Rousseau cited a naturalist's words, "The child has hardly left the mother's womb, it has hardly begun to move and stretch its limbs, when it is deprived of its freedom. It is wrapped in swaddling bands, laid down with his head fixed, its leg stretched out, and its arms by its sides; it is wound round with linen and bandages of all sorts so that it cannot move. It is fortunate if it has room to breathe, and it is laid on its side so that water which should flow from its mouth can escape, for it is not free to turn its head on one for this purpose." (Rousseau, 2008) Rousseau further points out, "From birth you are always checking them, your first gifts are fetters, your first treatment, torture."(Rousseau, 2008) Perhaps some people will argue that Rousseau is too extreme and ideal, and that even Rousseau himself cannot do as he says. In my opinion, Rousseau discovers the existence of children, stresses to respect children's nature in education, and opposes blind constraint on children by adults. His words are still warning us.

Sports are the natural instincts of animal. Without sports, they will become "vegetable". Certain report points out that the physique of Chinese and Japanese children are the same under 3 years old, but become different above 3 years old. In detail, cardio-pulmonary function of Chinese children declines, athletic ability decreases, and detection rate of poor sight rises constantly. Therefore, it is very important to guarantee infants' sports activities. Here we stress outdoor sports activities, as we live in concrete urban buildings. Narrow, small, simple man-made environment full of radiation after decoration is inferior to outdoor, broad, complex and green natural environment. Outdoor activities are essential for children when they grow up. For children under 2 years old, the major sports are crawling and walking and they need adult's enough support and training. During human beings' development from primate to human, crawling plays an important role. Crawling is of great significance for an infant. Before an infant is able to walk, crawling broadens its range of activity in advance. As a result, infant's perception, intention, enough stimulation to brain nerve cell can develop in advance, improving the starting point of intelligence. For children between 2 and 6 years old, the key point in sports activities is to give him enough space and freedom for activities after guaranteeing security.

In terms of the exertion of young children's right to sports activities, there may be two extremes. On the one hand, they don't take part in enough sports activities due to control of adults; On the other hand, they tend to make excessive exercise under the interference of adults. The former points out major object that sports activities need to precaution against, which is also the key point in the above discussions. At the same time, we also have to precaution against the latter problem. Under the direction of utilitarian thoughts, like great ambitions for their children for some Chinese parents, the hope that their children can become sports stars and world champion one day, a slogan that "we cannot lose at the starting line", sports activities of young children become abuse. The standard of proper exercise depends on young children's physical development and psychological mechanism. 
Adults' any good wishes for young children's sports have to be based on children's physical and mental index, instead of adults' ideal. In recent years, the media have disclosed several accidents about excessive exercise, such as Wang Tieming accident, "a two-year-old girl climbs to the top of Mount Qingcheng in six hours", and "naked boy runner". In addition, we have to pay attention to athletic training of young children in professional sports school. Due to lack of special research, the author cannot analyze in detail. However, according to information disclosed by the media, there may be excessive training for children in professional sports school.

\section{Conclusions}

The rights of young children to health are divided into the right to eutocia, the right to food, the right to space and the right to sports activities. The basis and standard for such a division includes two aspects. On one hand, there is the timeliness and importance of each sub-rights to young children; on the other hand, it is a result of current Chinese society, economic life and other factors affecting the realization of the rights to health. From the vertical perspective, the right to eutocia is an essential right from an embryo to a natural person; from the horizontal one, the right to food is the basis and premise of the right to space and the right to sports activities. In other words, the right to space and the right to sports activities are void for a child without the right to food. Without the right to space and the right to sports activities, the health of a child with only right to food cannot be guaranteed. The right to eutocia belongs to embryos exclusively; the right to food, the right to space and the right to sports activities belong to all natural people. Compared with adults, limited capacity for action and independent choice of young children affect their exertion of corresponding rights. To regard the right to food, the right to space and right to sports activities as the main content of the rights of young children to health is both special protection for young children's health and effective guarantee for adults to achieve the best interest of the children. This study on classification of the rights of young children to health which belongs to basic research is good for enriching the content of the right to health and realizing the characteristics of the right to young children. To some extent, the degree of realization these sub-rights from legal rights to actual rights is a standard of how the rule of law goes in one state's sanitation and education fields.

\section{References}

Desmond, M. (2010). The Naked Ape (pp. 192, 195, He Daokuan trans.). Shanghai: Fudan University Publishing House.

$\mathrm{Hu}$, B. S. (2004). Influential Factors of Breastfeeding in Married Woman at Child-bearing Age in Five Cities of China. Maternal \& Child Health Care of China, 19(18).

Lin, Z. Q. (2010). Study of Health Right (pp. 177-202). Beijing: China Legal Publishing House.

Littell, A., Wiggin, \& Dana, L. L. P. (2002, Fall). Can a constitutional right to health guarantee universal health care coverage or improved health outcomes? A survey of selected states. Connecticut Law Review, 35(1), 289-318.

Liu, J. (2006). The Analysis on the Influential Factors of Breastfeeding. Maternal \& Child Health Care of China, (15).

Mao, Z. Y. (2012). Thoughts on the Right of Women Workers to Breastfeeding in China. Collection of Women's Studies, (1).

Otto, F. B. (1999). Educational Anthropology (p. 41, Li Qilong trans.). Shanghai: East China Normal University Press.

Pang, R. Y. (2012). The Current Situation of and Countermeasures to Cesarean section in China. Journal of Practical Obstetrics and Gynecology, (3).

Provisional agenda item on the $61^{\text {st }}$ conference of the UN Commission on Human Rights. Right to food. The report of special rapporteur Jean Ziegler. Retrieved December 9, 2012, from http://www.un.org/chinese/hr/issue/food.htm

Qian, X. (2012). Analysis on the Status and Factors Influencing the Breastfeeding of Children under 2 years of age in Poverty Stricken Areas of China in 2007-2009. Journal of Hygiene Research, (1).

Rousseau. (2008). Émile: on Education (Vol. 1, pp. 15-16, Li Pingou trans.). Beijing: The Commercial Press.

Sun, X. Z. (2012). Children's Right to Health Protection Research (Master's thesis, pp. 11-13). Southwest University of Political Science and Law.

UNICEF. (2006). A Guide to General Comment 7: 'Implementing Child Rights in Early Childhood'. Retrieved from http://www.unicef.org/earlychildhood/files/Guide_to_GC7.pdf 
Wang, L. M. (2007). Space Right: a New Kind of Property Right. Science of Law in Journal of Northwest University of Politics and Law, (2).

Xu, G. D. (2007). General Regulation of Civil Law (pp. 319-321). Beijing: Higher Education Press.

Yang, M. (2012). Analysis on the Effect Factors of Pure Breastfeeding among the Rural Infants in Five Provinces of Western China. Maternal \& Child Health Care of China, (27).

Yang, M. (2012). Analysis on the Effect Factors of Pure Breastfeeding among the Rural Infants in Five Provinces of Western China. Maternal \& Child Health Care of China, (27).

Yu, J. P. (2006). Analysis of Causes of 581 Cesarean section. Chinese Journal of Obstetrics \& Gynecology and Pediatrics, (5).

\section{Acknowledgements}

This research was funded by the school starting program in China West Normal University (No. 13E007). I am also grateful to anonymous reviewers for their advice and suggestion. However, any mistakes that remain are my own.

\section{Copyrights}

Copyright for this article is retained by the author(s), with first publication rights granted to the journal.

This is an open-access article distributed under the terms and conditions of the Creative Commons Attribution license (http://creativecommons.org/licenses/by/3.0/). 